\title{
Vertical Fluxes Induced by Weak-Nonlinear Internal Waves in a Baroclinic Flow
}

\author{
A.A. Slepyshev \\ Marine Hydrophysical Institute, Russian Academy of Sciences, Sevastopol, \\ Russian Federation
}

\begin{abstract}
In a Bussinesq approximation free internal waves are considered at the account of turbulent viscosity and diffusion in a vertically-non-uniform flow. In linear approximation the dispersive relation and decrement of wave attenuation are found. The equation for amplitude of the vertical velocity, containing small parameter at the higher derivative, proportional to turbulent viscosity, solved by Ljusternik-Vishik asymptotic method. Boundary-layer solution on a vicinity of a bottom and a free surface are found. The non-viscous boundary value problem of the second order is solved numerically according to an Adams's implicit scheme of the third order accuracy. The wave number at the fixed frequency of a wave is found by a shooting method. Stokes drift velocity and vertical wave flux of salt are determined in the second order on wave amplitude. Shift of phases between fluctuations of salinity and vertical velocity with regard to turbulent viscosity and diffusion differs from $\pi / 2$, therefore the vertical wave flux of salt differs from zero. The dispersive parity, decrement of wave attenuation and wave fluxes are calculated for internal waves observed during the 3rd stage of the 44 cruise of R/V "Mikhail Lomonosov" to the northwest shelf of the Black sea. Critical layers for a current profile were absent at the test site (where the measurements were carried out), i.e. phase rate of internal waves exceeded the current velocity. It is shown that out of a layer with the maximum gradient of salinity, i.e. out of surface layer, the wave flux of salt is comparable in absolute value with the turbulent one. In a surface layer turbulent flux of salt exceeds the wave one. The consideration of current results in slight decrease of the wave flux. Horizontal component of Stokes drift velocity, which is transversal to the wave propagation direction, differs from zero and is one order less than longitudinal one when taking into account the current.
\end{abstract}

Keywords: internal waves, turbulence, Stokes drift.

DOI: 10.22449/1573-160X-2015-1-59-72

(C) 2015, A.A. Slepyshev

(C) 2015, Physical Oceanography

Introduction. Internal waves are presented everywhere in the ocean due to effect of sources which generate them. Internal waves can exist in stratified medium when water density increases with the depth. Below the upper mixed layer such situation is typical for the World Ocean. Atmospheric pressure perturbations, wind stresses on the sea surface, interaction of tides and currents with bottom topography inhomogeneities [1], eddy currents may be referred to internal wave energy sources.

Actuality of the problems is related to the fact that internal waves can contribute to vertical transfer in the ocean. Usually, vertical transfer in marine environment is connected with small-scaled turbulence that has an intermittent character, i. e. the turbulence is presented in the form of "patches", generated by hydrodynamic instability of currents and breaking of internal waves. Vertical transfer plays an important role in admixture transport, oxygen diffusion to the deep layers of the sea and hydrogen sulphide diffusion from deep layers of the Black Sea.

The internal waves with regard for eddy viscosity and diffusion were considered in a number of works [1 - 3], where a decrement of wave attenuation on PHYSICAL OCEANOGRAPHY NO. 1 (2015) 
turbulence was determined. Non-linear effects at wave propagation with no regard for eddy viscosity and diffusion were considered in $[4,5]$. In these works a mean wave-induced current and non-oscillatory correction to the average density were determined.

Internal waves with regard for nonlinearity and viscosity were considered in [6], but vertical wave fluxes of heat and salt were not taken into account.

Vertical transfer in stratified seawater column is associated with breaking of small-scale internal wave [7], and turbulent energy dissipation rate and a coefficient of vertical eddy diffusivity are estimated. It is shown that in the area of continental slope at the edge of the Black Sea shelf the intensification of vertical transfer, related with internal wave amplitude increase at their propagation to the shallow water area [8], takes place.

Vertical flows, determined by weak-nonlinear internal waves, were considered in [9]. Such flows exist due to vertical velocity and temperature (salinity) oscillation phase shift, which differs from $\pi / 2$ when diffusion and eddy viscosity are taken into account.

In the given work the vertical flows caused by internal waves on the baroclinic flow are considered. It is of interesting to compare wave fluxes with the corresponding turbulent fluxes both in the presence of current and in the absence of it. Moreover, the Stokes drift speed in both these cases is found.

Formulation of the problem. Free internal waves on the baroclinic flow with account for eddy viscosity and diffusion in the Boussinesq approximation are considered. Internal wave amplitude distribution, dispersive relation and wave attenuation decrement are calculated in linear approximation. The Stokes drift speed and wave fluxes of salt are found in the second order of the wave amplitude.

We introduce dimensionless variables by the following formulas (dimensional physical quantities are denoted by wavy lines above the symbols):

$$
\begin{gathered}
\tilde{t}=\frac{t}{\omega_{*}}, \quad \tilde{k}=\frac{k}{H}, \quad \tilde{\omega}=\omega_{*} \omega, \quad \tilde{u}_{1}=u_{1} H \omega_{*}, \quad \tilde{u}_{2}=u_{2} H \omega_{*} \quad \tilde{u}_{3}=u_{3} H \omega_{*}, \\
\tilde{P}=\bar{\rho}_{0} H^{2} \omega_{*}^{2} P, \quad \tilde{\rho}=\bar{\rho}_{0} \omega_{*}^{2} \frac{H \rho}{g}, \quad \tilde{\rho}_{0}=\bar{\rho}_{0} \omega_{*}^{2} \frac{H \rho_{0}}{g}, \quad \tilde{x}_{i}=H x_{i}, \quad \tilde{K}_{i}=K_{i} \mu_{i}, \\
\tilde{M}_{i}=M_{i} \mu_{i} \quad(i=1,2,3), \quad K_{1}=K_{2}, \quad M_{1}=M_{2}, \quad \mu_{1}=\mu_{2},
\end{gathered}
$$

where $\mu_{1}, \mu_{3}$ - are the characteristic values of horizontal and vertical eddy viscosity; $g-$ is an acceleration of gravity; $x_{1}, x_{2}, x_{3}$ - are two horizontal and one vertical coordinates, vertical axis $x_{3}$ is directed vertically upwards; $\rho$ and $P$ - are the wave perturbations of the density and pressure; $\rho_{0}$ - is an unperturbed average water density; $\bar{\rho}_{0}$ - is a depth-averaged density; $u_{1}, u_{2}, u_{3}$ - are two horizontal and one vertical components of velocity wave disturbances; $K_{1}, K_{3}, M_{1}, M_{3}$ - are horizontal and vertical coefficients of eddy viscosity and diffusion, respectively; $H-$ is a sea depth; $\omega_{*}-$ is a characteristic wave 
frequency. The coefficients of vertical eddy diffusivity and viscosity, and two components of the mean current velocity $U_{0}, V_{0}$ are assumed to be dependent on the vertical coordinate. The coefficients of horizontal eddy diffusivity and viscosity are assumed to be constant. The system of hydrodynamic equations for the wave disturbances in the Boussinesq approximation has the following form:

$$
\begin{gathered}
\frac{\partial u_{1}}{\partial t}+u_{i} \frac{\partial u_{1}}{\partial x_{i}}+U_{0} \frac{\partial u_{1}}{\partial x_{1}}+V_{0} \frac{\partial u_{1}}{\partial x_{2}}+u_{3} \frac{d U_{0}}{d x_{3}}=-\frac{\partial P}{\partial x_{1}}+\varepsilon^{2} K_{1}\left(\frac{\partial^{2} u_{1}}{\partial x_{1}^{2}}+\frac{\partial^{2} u_{1}}{\partial x_{2}^{2}}\right)+ \\
+\varepsilon^{2} \beta^{2} \frac{\partial}{\partial x_{3}}\left(K_{3} \frac{\partial u_{1}}{\partial x_{3}}\right) \\
\frac{\partial u_{2}}{\partial t}+u_{i} \frac{\partial u_{2}}{\partial x_{i}}+U_{0} \frac{\partial u_{2}}{\partial x_{1}}+V_{0} \frac{\partial u_{2}}{\partial x_{2}}+u_{3} \frac{\partial V_{0}}{\partial x_{3}}=-\frac{\partial P}{\partial x_{2}}+\varepsilon^{2} K_{1}\left(\frac{\partial^{2} u_{2}}{\partial x_{1}^{2}}+\frac{\partial^{2} u_{2}}{\partial x_{2}^{2}}\right)+ \\
+\varepsilon^{2} \beta^{2} \frac{\partial}{\partial x_{3}}\left(K_{3} \frac{\partial u_{2}}{\partial x_{3}}\right) \\
\frac{\partial u_{3}}{\partial t}+u_{i} \frac{\partial u_{3}}{\partial x_{i}}+U_{0} \frac{\partial u_{3}}{\partial x_{1}}+V_{0} \frac{\partial u_{3}}{\partial x_{2}}=-\frac{\partial P}{\partial x_{3}}+\varepsilon^{2} K_{1}\left(\frac{\partial^{2} u_{3}}{\partial x_{1}^{2}}+\frac{\partial^{2} u_{3}}{\partial x_{2}^{2}}\right)+ \\
+\varepsilon^{2} \beta^{2} \frac{\partial}{\partial x_{3}}\left(K_{3} \frac{\partial u_{3}}{\partial x_{3}}\right)+\varepsilon^{2} \beta^{2} \frac{\partial K_{3}}{\partial x_{3}} \frac{\partial u_{3}}{\partial x_{3}}-\rho, \\
\frac{\partial \rho}{\partial t}+u_{i} \frac{\partial \rho}{\partial x_{i}}+U_{0} \frac{\partial \rho}{d x_{1}}+V_{0} \frac{\partial \rho}{d x_{2}}=\varepsilon^{2} M_{1}\left(\frac{\partial^{2} \rho}{\partial x_{1}^{2}}+\frac{\partial^{2} \rho}{\partial x_{2}^{2}}\right)+\varepsilon^{2} \beta^{2} \frac{\partial}{\partial x_{3}}\left(M_{3} \frac{\partial \rho}{\partial x_{3}}\right)-u_{3} \frac{\partial \rho_{0}}{\partial x_{3}} \\
\frac{\partial u_{i}}{\partial x_{i}}=0
\end{gathered}
$$

Here $\varepsilon^{2}=\frac{\mu_{1}}{H^{2} \omega_{*}}-$ is a small parameter proportional to the value of the horizontal eddy viscosity coefficient $\mu_{1} ; \beta^{2}=\frac{\mu_{3}}{\mu_{1}}$, while $\beta^{2}<<\varepsilon^{2}$.

Boundary conditions on the surface are the solid top condition and the absence of tangential stresses [2]:

$$
u_{3}(0)=0, \quad \beta^{2} K_{3} \frac{\partial u_{1}}{\partial x_{3}}+K_{1} \frac{\partial u_{3}}{\partial x_{1}}=\left.0\right|_{x_{3}=0}, \quad \beta^{2} K_{3} \frac{\partial u_{2}}{\partial x_{3}}+K_{1} \frac{\partial u_{3}}{\partial x_{2}}=\left.0\right|_{x_{3}=0}
$$

Boundary conditions on the bottom are the adhesion conditions:

$$
u_{1}(-1)=0, \quad u_{2}(-1)=0, \quad u_{3}(-1)=0 .
$$


Linear approximation. We seek the solutions of linear approximation in the following form:

$$
\begin{gathered}
u_{1}^{0}=u_{10}\left(x_{3}\right) A \mathrm{e}^{\mathrm{i} \theta}+\text { c.C. }, \quad u_{2}^{0}=u_{20}\left(x_{3}\right) A \mathrm{e}^{\mathrm{i} \theta}+\text { c.C. }, \quad u_{3}^{0}=u_{30}\left(x_{3}\right) A \mathrm{e}^{\mathrm{i} \theta}+\text { c.C. }, \\
P_{1}=P_{10}\left(x_{3}\right) A \mathrm{e}^{\mathrm{i} \theta}+\text { c.C. }, \quad \rho_{1}=\rho_{10}\left(x_{3}\right) A \mathrm{e}^{\mathrm{i} \theta}+\text { c.C. },
\end{gathered}
$$

where c.c. - are complex conjugate terms; $A$ - amplitude factor; $\theta$ - wave phase; $\frac{\partial \theta}{\partial x_{1}}=k ; \frac{\partial \theta}{\partial t}=-\omega$ ( $k$ - wave number, $\omega-$ frequency). It is assumed that the wave propagates along the $x_{1}$ axis.

Substituting (4) into the system of equations (1), we obtain the relation of amplitude functions $u_{10}, P_{10}, u_{30}$ and equation for $u_{20}\left(x_{3}\right), \rho_{10}\left(x_{3}\right)$ :

$$
\begin{gathered}
u_{10}=\frac{i}{k} \frac{\partial u_{30}}{\partial x_{3}}, \quad \Omega=\omega-k U_{0}, \\
P_{10}=\left(\varepsilon^{2} \beta^{2} K_{3} \frac{d^{2}}{d x_{3}^{2}}+\varepsilon^{2} \beta^{2} \frac{d K_{3}}{d x_{3}} \frac{d}{d x_{3}}+i \Omega-\varepsilon^{2} K_{1} k^{2}\right) \frac{1}{k^{2}} \frac{d u_{30}}{d x_{3}}+\frac{i}{k} \frac{d U_{0}}{d x_{3}} u_{30}, \\
\left(\varepsilon^{2} \beta^{2} M_{3} \frac{d^{2}}{d x_{3}^{2}}+\varepsilon^{2} \beta^{2} \frac{d M_{3}}{d x_{3}} \frac{d}{d x_{3}}-\varepsilon^{2} M_{1} k^{2}+i \Omega\right) \rho_{10}=u_{30} \frac{d \rho_{0}}{d x_{3}} \\
\varepsilon^{2} \beta^{2} K_{3} \frac{d^{2} u_{20}}{d x_{3}^{2}}+\varepsilon^{2} \beta^{2} \frac{d K_{3}}{d x_{3}} \frac{d u_{20}}{d x_{3}}+\left(i \Omega-\varepsilon^{2} K_{1} k^{2}\right) u_{20}=u_{30} \frac{d V_{0}}{d x_{3}} .
\end{gathered}
$$

(5d) equation should be supplemented by boundary conditions arising from (2), (3):

$$
\left.\frac{d u_{20}}{d x_{3}}\right|_{x_{3}=0}=0 ;\left.\quad u_{20}\right|_{x_{3}=-1}=0 .
$$

The function $u_{30}$ satisfies the equation

$$
\begin{aligned}
& -N^{2} u_{30}=\left(\varepsilon^{2} \beta^{2} M_{3} \frac{d^{2}}{d x_{3}^{2}}+\varepsilon^{2} \beta^{2} \frac{d M_{3}}{d x_{3}} \frac{d}{d x_{3}}-\varepsilon^{2} M_{1} k^{2}+i \Omega\right) \times \\
& \times\left\{i \Omega u_{30}-\frac{d}{d x_{3}}\left[\left(\varepsilon^{2} \beta^{2} K_{3} \frac{d^{2}}{d x_{3}^{2}}+\varepsilon^{2} \beta^{2} \frac{d K_{3}}{d x_{3}} \frac{d}{d x_{3}}-\varepsilon^{2} K_{1} k^{2}+i \Omega\right) \frac{1}{k^{2}} \frac{d u_{30}}{d x_{3}}+\frac{i}{k} \frac{d U_{0}}{d x_{3}} u_{30}\right]-\right. \\
& \left.-\varepsilon^{2} K_{1} k^{2} u_{30}+\varepsilon^{2} \beta^{2} K_{3} \frac{d^{2} u_{30}}{d x_{3}^{2}}+2 \varepsilon^{2} \beta^{2} \frac{d K_{3}}{d x_{3}} \frac{d u_{30}}{d x_{3}}\right\} .
\end{aligned}
$$

From the boundary conditions (2), (3) we obtain the conditions for $u_{30}$ :

on the surface at $x_{3}=0$

$$
u_{30}=0, \quad \frac{d^{2} u_{30}}{d x_{3}^{2}}=0,
$$


on the bottom at $x_{3}=-1$

$$
u_{30}=\frac{d u_{30}}{d x_{3}}=0
$$

Equation (7) has a small parameter at the higher derivative $\sim(\varepsilon \beta)^{4}$. We solve this equation, following $[10,11]$, by the Lusternik - Vishik asymptotical method, expanding $u_{30}, \omega$ in series by $\varepsilon \beta$ small parameter:

$$
\begin{gathered}
u_{30}\left(x_{3}\right)=\sum_{i=0}(\varepsilon \beta)^{i} u_{3 i}^{0}\left(x_{3}, \varepsilon\right)+\varepsilon \beta \sum_{i=0}(\varepsilon \beta)^{i} v_{i}^{1}+(\varepsilon \beta)^{2} \sum_{i=0}(\varepsilon \beta)^{i} v_{i}^{0}, \\
\omega=\omega_{01}(\varepsilon)+\varepsilon \beta \omega_{11}(\varepsilon)+(\varepsilon \beta)^{2} \omega_{21}(\varepsilon)+\ldots,
\end{gathered}
$$

where $v_{i}^{1}\left(\left(1+x_{3}\right) / \varepsilon \beta\right)$ - boundary layer solution in the neighborhood of the bottom, $v_{i}^{0}\left(x_{3} / \varepsilon \beta\right)$ - in the neighborhood of free surface. Boundary layer corrections are the functions, rapidly decreasing with the distance from the boundary, which provide the execution of the boundary conditions. In the general case the functions $u_{3 i}\left(x_{3}, \varepsilon\right)$ depend on the parameter $\varepsilon$, because it is contained in the equations for these functions.

Substituting the expansions (9) in (7), we obtain the boundary value problem for the function $u_{30}^{0}$ in the first order on $\varepsilon \beta$ parameter:

$$
\left(\varepsilon^{2} M_{1} k^{2}-i \Omega_{01}\right)\left\{i \Omega_{01} u_{30}^{0}-\frac{d}{d x_{3}}\left[\left(i \Omega_{01}-\varepsilon^{2} K_{1} k^{2}\right) \frac{1}{k^{2}} \frac{d u_{30}^{0}}{d x_{3}}+\frac{i}{k} \frac{d U_{0}}{d x_{3}} u_{30}^{0}-\varepsilon^{2} K_{1} k^{2} u_{30}^{0}\right]\right\}=N^{2} u_{30}^{0},
$$

where $N^{2}=-\frac{d \rho_{0}}{d x_{3}}-$ square of the Brent-Vaissala frequency; $\Omega_{01}=\omega_{01}-k U_{0}-$ wave frequency with Doppler shift.

Boundary conditions for $u_{30}^{0}$ are the following:

$$
\left.u_{30}^{0}\right|_{x_{3}=0}=0,\left.\quad u_{30}^{0}\right|_{x_{3}=-1}=0 .
$$

The equation (10) has a small parameter $\varepsilon$ and following the method, described in [10], we seek the solution and frequency $\omega_{01}$ in a form of asymptotic series by this parameter:

$$
\begin{gathered}
u_{30}^{0}\left(x_{3}, \varepsilon\right)=w_{0}\left(x_{3}\right)+\varepsilon w_{1}\left(x_{3}\right)+\varepsilon^{2} w_{2}\left(x_{3}\right)+\ldots, \\
\omega_{01}=\omega_{0}+\varepsilon \omega_{1}+\varepsilon^{2} \omega_{2}+\ldots
\end{gathered}
$$


In a zero order on parameter $\varepsilon$ function $w_{0}$ satisfy boundary value problem

$$
\begin{gathered}
\frac{d^{2} w_{0}}{d x_{3}^{2}}+k^{2} \frac{\left(N^{2}-\Omega_{0}^{2}\right)}{\Omega_{0}^{2}} w_{0}+\frac{k}{\Omega_{0}} \frac{d^{2} U_{0}}{d x_{3}^{2}} w_{0}=0, \\
\left.w_{0}\right|_{x_{3}=0}=0,\left.\quad w_{0}\right|_{x_{3}=-1}=0,
\end{gathered}
$$

Where $\Omega_{0}=\omega_{0}-k U_{0}$. In the absence of singularity $\Omega_{0}=0$ the boundary value problem (13) has a numerable set of eigenfunctions - a set of modes and for any value of frequency $\omega_{0}<\max (N)$ corresponds a certain wave number $k$ for given mode.

The next term in the expansion (12a) is determined from the following equation

$$
\frac{d^{2} w_{1}}{d x_{3}^{2}}+k^{2} \frac{\left(N^{2}-\Omega_{0}^{2}\right)}{\Omega_{0}^{2}} w_{1}+\frac{k}{\Omega_{0}} \frac{d^{2} U_{0}}{d x_{3}^{2}} w_{1}=\frac{\omega_{1}}{\Omega_{0}}\left(2 k^{2} w_{0}-2 \frac{d^{2} w_{0}}{d x_{3}^{2}}-\frac{k w_{0}}{\Omega_{0}} \frac{d^{2} U_{0}}{d x_{3}^{2}}\right)=f_{1}\left(x_{3}\right)
$$

Boundary conditions for $w_{1}$ function

$$
\left.w_{1}\right|_{x_{3}=0}=0,\left.\quad w_{1}\right|_{x_{3}=-1}=0 .
$$

The solvability condition of the boundary value problem (14), (15)

$$
\int_{-1}^{0} f_{1} w_{0} d x_{3}=0 .
$$

For $\omega_{1} \neq 0$ this condition is not generally fulfilled and the boundary value problem (14), (15) has no solutions.

The next approximation $w_{2}$ in the parameter $\varepsilon$ satisfies the following equation

$$
\begin{aligned}
& \Omega_{0}^{2}\left[\frac{d^{2}}{d x_{3}^{2}}-k^{2}\right] w_{2}+ N^{2} k^{2} w_{2}+k \Omega_{0} \frac{d^{2} U_{0}}{d x_{3}^{2}} w_{2}=\left(\omega_{2}+i M_{1} k^{2}\right)\left(k^{2} \Omega_{0} w_{0}-\Omega_{0} \frac{d^{2} w_{0}}{d x_{3}^{2}}-k \frac{d^{2} U_{0}}{d x_{3}^{2}} w_{0}\right)+ \\
&+\Omega_{0}\left[\omega_{2}\left(k^{2} w_{0}-\frac{d^{2} w_{0}}{d x_{3}^{2}}\right)-i K_{1} k^{2} \frac{d^{2} w_{0}}{d x_{3}^{2}}+i K_{1} k^{4} w_{0}\right]=\Phi .
\end{aligned}
$$

Boundary conditions for $w_{2}$ have the following form

$$
\left.w_{2}\right|_{x_{3}=0}=0,\left.\quad w_{2}\right|_{x_{3}=-1}=0 .
$$

Solvability condition of the boundary value problem (17), (18)

$$
\int_{-1}^{0} \Phi w_{0} d x_{3}=0
$$


Hence we find the expression for $\omega_{2}$ :

$$
\omega_{2}=-i \frac{\int_{-1}^{0}\left(\frac{M_{1} k^{4}}{\Omega_{0}^{2}} N^{2} w_{0}-K_{1} k^{2} \frac{d^{2} w_{0}}{d x_{3}^{2}}+k^{4} K_{1} w_{0}\right) \frac{w_{0}}{\Omega_{0}} d x_{3}}{\int_{-1}^{0}\left(\frac{N^{2}}{\Omega_{0}^{3}} 2 k^{2}+\frac{k}{\Omega_{0}^{2}} \frac{d^{2} U_{0}}{d x_{3}^{2}}\right) w_{0}^{2} d x_{3}} .
$$

Let us find a boundary layer solution $v_{0}^{0}$ in the expansion (9a) to satisfy the boundary conditions (8a), (8b) on the surface. Substituting the expansion (9a) in the equation (7), and expanding $K_{3}, M_{3}$ and $U_{0}, V_{0}$ in Taylor series in the neighborhood $x_{3}=0$ we obtain the equation for $v_{0}^{0}(\eta)$, in the zero order on parameter $\varepsilon \beta$ :

$$
K_{3}(0) M_{3}(0) \frac{\partial^{6} v_{0}^{0}}{\partial \eta^{6}}+i \Omega_{0}(0)\left(K_{3}(0)+M_{3}(0)\right) \frac{\partial^{4} v_{0}^{0}}{\partial \eta^{4}}=\Omega_{0}^{2}(0) \frac{\partial^{2} v_{0}^{0}}{\partial \eta^{2}}, \quad \eta=\frac{x_{3}}{\varepsilon \beta} .
$$

The solution of the equation (21), attenuating with the distance from the surface, has the following form:

$$
v_{0}^{0}=C_{0}^{0} \exp \left(\lambda_{1}^{0} \eta\right)+F_{0}^{0} \exp \left(\lambda_{2}^{0} \eta\right)
$$

where

$$
C_{0}^{0}=\frac{d^{2} w_{0}(0)}{d x_{3}^{2}} \frac{1}{\left(\lambda_{2}^{0}\right)^{2}-\left(\lambda_{1}^{0}\right)^{2}}, \quad F_{0}^{0}=-C_{0}^{0} .
$$

Here $\lambda_{1}^{0}, \lambda_{2}^{0}$ are calculated according to the formulas

$$
\lambda_{1}^{0}=\left(\frac{\Omega_{0}(0)}{2 M_{3}(0)}\right)^{1 / 2}(1-i), \quad \lambda_{2}^{0}=\left(\frac{\Omega_{0}(0)}{2 K_{3}(0)}\right)^{1 / 2}(1-i) .
$$

The equation for the boundary layer solution $v_{0}^{1}\left(\left(1+x_{3}\right) / \varepsilon_{2}\right)$ has the following form:

$$
\frac{\partial^{6} v_{0}^{1}}{\partial \eta_{1}^{6}}+i \Omega_{0}(-1) \frac{M_{3}+K_{3}}{M_{3} K_{3}} \frac{\partial^{4} v_{0}^{1}}{\partial \eta_{1}^{4}}-\frac{\Omega_{0}^{2}}{M_{3} K_{3}} \frac{\partial^{2} v_{0}^{1}}{\partial \eta_{1}^{2}}=0,
$$

where $\eta_{1}=\frac{\left(x_{3}+1\right)}{\varepsilon \beta}$. The solution of the given equation, attenuating with the distance from the bottom and satisfying the boundary conditions (8b), is determined by formula:

$$
v_{0}^{1}=D_{0}^{1} \exp \left(-\lambda_{1} \eta_{1}\right)+G_{0}^{1} \exp \left(-\lambda_{2} \eta_{1}\right),
$$

where

$$
D_{0}^{1}=\frac{d w_{0}(-1)}{d x_{3}} \frac{1}{\lambda_{1}-\lambda_{2}}, \quad G_{0}^{1}=-D_{0}^{1}
$$


The values $\lambda_{1}, \lambda_{2}$ are calculated according to the formulas (24), only the eddy transfer coefficients and wave frequency with the Doppler shift are calculated at the lower boundary.

The equation for salinity wave perturbations $s$ has the form

$$
\begin{aligned}
& \frac{\partial s}{\partial t}+\left(u_{1}+U_{0}\right) \frac{\partial s}{\partial x_{1}}+\left(u_{2}+V_{0}\right) \frac{\partial s}{\partial x_{2}}+u_{3} \frac{\partial s}{\partial x_{3}}+u_{3} \frac{\partial S_{0}}{\partial x_{3}}=\varepsilon^{2} \frac{\partial}{\partial x_{1}}\left(M_{1} \frac{\partial s}{\partial x_{1}}\right)+ \\
& +\varepsilon^{2} \frac{\partial}{\partial x_{2}}\left(M_{1} \frac{\partial s}{\partial x_{2}}\right)+(\varepsilon \beta)^{2} \frac{\partial}{\partial x_{3}}\left(M_{3} \frac{\partial s}{\partial x_{3}}\right),
\end{aligned}
$$

where $S_{0}\left(x_{3}\right)-$ is an average salinity profile. The solutions of linear approximation will be sought in the following form:

$$
s_{1}=s_{10}\left(x_{3}\right) A \mathrm{e}^{i \theta}+\text { c.C. },
$$

where $S_{10}$ satisfies the equation

$$
-i \Omega s_{10}+u_{30} \frac{d S_{0}}{d x_{3}}=\varepsilon^{2}\left(-k^{2} M_{1} s_{10}+\beta^{2} \frac{d}{d x_{3}}\left(M_{3} \frac{d s_{10}}{d x_{3}}\right)\right) .
$$

Equation (29) has a small parameter at the higher derivative, and we are to seek a solution at the form similar to (9a):

$$
s_{10}=s_{10}^{I}+(\varepsilon \beta)^{2} s_{10}^{I I}+\varepsilon \beta \sum_{i=0} s_{\Pi i}^{I}\left(\frac{x_{3}+1}{\varepsilon \beta}\right)(\varepsilon \beta)^{i}+(\varepsilon \beta)^{2} \sum_{i=0} s_{\Pi i}^{0}\left(\frac{x_{3}}{\varepsilon \beta}\right)(\varepsilon \beta)^{i} .
$$

From (29) it follows that

$$
S_{10}{ }^{I}=s_{0}+\varepsilon^{2} S_{2}+\ldots
$$

where

$$
\begin{gathered}
s_{0}=-\frac{i w_{0}}{\Omega_{0}} \frac{d S_{0}}{d x_{3}}, \\
s_{2}=-\left(\omega_{2 i}+k^{2} M_{1}\right) \frac{w_{0}}{\Omega_{0}^{2}} \frac{d S_{0}}{d x_{3}}-\frac{i w_{2}}{\Omega_{0}} \frac{d S_{0}}{d x_{3}},
\end{gathered}
$$

here $\omega_{2 i}=\frac{\omega_{2}}{i}$. Boundary layer solutions $s_{\Pi 0}^{I}$ and $s_{\Pi 0}^{0}$ in the neighborhood of the bottom and free surface satisfy the following equations, respectively

$$
\begin{aligned}
& i \Omega_{0}(0) s_{\Pi 0}^{0}+\frac{d}{d \eta}\left(M_{3}(0) \frac{d}{d \eta}\right) s_{\Pi 0}^{0}=\frac{d S_{0}(0)}{d x_{3}} v_{0}^{0}(\eta), \\
& i \Omega_{0}(-1) s_{\Pi 0}^{I}+\frac{d}{d \eta_{1}}\left(M_{3}(-1) \frac{d}{d \eta_{1}}\right) s_{\Pi 0}^{I}=\frac{d S_{0}(-1)}{d x_{3}} v_{0}^{1}\left(\eta_{1}\right) .
\end{aligned}
$$

Boundary conditions have the form

$$
S_{10}(0)=S_{10}(-1)=0 \text {. }
$$


Solution of the equation (33a) in the neighborhood of the sea surface is the following:

$$
s_{\Pi 0}^{0}(\eta)=C_{1 S}^{0} \exp \left(\lambda_{1}^{0} \eta\right)+Q_{S}^{0} \exp \left(\lambda_{2}^{0} \eta\right)+\eta P_{S}^{0} \exp \left(\lambda_{1}^{0} \eta\right),
$$

where

$$
\begin{gathered}
P_{S}^{0}=\frac{C_{0}^{0}}{2 \lambda_{1}^{0} M_{3}(0)} \frac{d S_{0}(0)}{d x_{3}}, \\
Q_{S}^{0}=\frac{i C_{0}^{0}}{\Omega_{0}(0)\left[1-M_{3}(0) / K_{3}(0)\right]} \frac{d S_{0}(0)}{d x_{3}}, \\
C_{1 S}^{0}=-Q_{S}^{0} .
\end{gathered}
$$

Boundary layer solution of the equation (33b) in the neighborhood of the bottom has the following form:

$$
s_{\Pi 0}^{I}\left(\eta_{1}\right)=C_{12 S}^{0} \exp \left(-\lambda_{1} \eta_{1}\right)+Q_{S 1} \exp \left(-\lambda_{2} \eta_{1}\right)+\eta_{1} P_{S 1} \exp \left(-\lambda_{1} \eta_{1}\right),
$$

where

$$
\begin{gathered}
P_{S 1}=-\frac{D_{0}^{1}}{2 \lambda_{1} M_{3}(-1)} \frac{d S_{0}(-1)}{d x_{3}} \\
Q_{S 1}=\frac{i D_{0}^{1}}{\Omega_{0}(-1)\left[1-M_{3}(-1) / K_{3}(-1)\right]} \frac{d S_{0}(-1)}{d x_{3}} .
\end{gathered}
$$

From the boundary condition (34) it follows

$$
C_{12 S}^{0}=-Q_{S 1} \text {. }
$$

Nonlinear effects. The velocity of the Stokes drift of the fluid particles is determined by the formula [12]:

$$
\mathrm{u}_{\mathrm{s}}=\overline{\int_{0}^{t} \mathrm{u} d \tau \nabla \mathbf{u}}
$$

where $\mathrm{u}$ - is a field of Eulerian velocities, a horizontal bar means the averaging over the wave period. Horizontal velocity component of the Stokes drift (directed along the wave vector) in the second order of amplitude, has the following form:

$$
u_{1 s}=\frac{A_{1} A_{1}^{*}}{k}\left(\frac{2 \omega_{0}}{\omega \omega^{*}} \frac{d u_{30}}{d x_{3}} \frac{d u_{30}^{*}}{d x_{3}}+\frac{u_{30}}{\omega} \frac{d^{2} u_{30}^{*}}{d x_{3}^{2}}+\frac{u_{30}^{*}}{\omega^{*}} \frac{d^{2} u_{30}}{d x_{3}^{2}}\right) .
$$

Horizontal velocity component of the Stokes drift (transversal to the direction of wave propagation) is calculated according to the formula

$$
u_{2 s}=\frac{i A_{1} A_{1}^{*}}{\omega} \frac{d\left(u_{30} u_{20}^{*}\right)}{d x_{3}}+\text { c.c. }, \quad A_{1}=A \mathrm{e}^{\omega_{i} t} .
$$

At the presence of the mean current, whose velocity component $V_{0}$ (transversal to the direction of wave propagation) depends on vertical coordinate, the value $u_{2 s}$ differs from zero and in the non-viscous case is calculated as follows:

PHYSICAL OCEANOGRAPHY NO. 1 (2015) 


$$
u_{2 s}=-\frac{2 A_{1} A_{1}^{*}}{\omega_{0}} \frac{d}{d x_{3}}\left(\frac{w_{0}^{2}}{\Omega_{0}} \frac{d V_{0}}{d x_{3}}\right) .
$$

Vertical wave flux of salt $\overline{u_{3} S}$ taking into account the expansions (9a), (30), (31) determined by formula:

$$
\overline{u_{3} S} /\left|A_{1}^{2}\right|=w_{0}\left(\varepsilon^{2} s_{2}+\varepsilon \beta S_{\Pi 0}^{I}+(\varepsilon \beta)^{2} S_{\Pi 0}^{0}\right)^{*}+s_{0}^{*}\left(\varepsilon \beta v_{0}^{1}+(\varepsilon \beta)^{2} v_{0}^{0}\right)+\varepsilon^{2} w_{2} s_{0}^{*}+\text { c.c. }
$$

Calculation results. Let us calculate salt wave fluxes for the internal waves, which had been observed southwestward of Yevpatoria during the experiment, performed at the third stage of the $44^{\text {th }} \mathrm{R} / \mathrm{V}$ Mikhail Lomonosov cruise.

In Fig. 1 we have plotted four realizations of the temperature contour elevations calculated according to the data of the GRAD instruments, that is to say, the gradient-distributed temperature gauges [13]. The first device was situated in 5 - $15 \mathrm{~m}$ layer, the second - in 15 - $25 \mathrm{~m}$ layer, the third - in 25 - $35 \mathrm{~m}$ layer and the fourth - in $35-60 \mathrm{~m}$ layer. It is obvious that strong oscillations with $15 \mathrm{~m}$ period in $25-60 \mathrm{~m}$ layer are in against phase with the oscillations in $25-60 \mathrm{~m}$ layer, which indicates the oscillations of the second mode. The maximum amplitude by swells made up $0.5 \mathrm{~m}$. In Fig. 2, $a, b$ the vertical profiles of the BrentVaissala frequency and two components of the current velocity are represented. The boundary value problem (13) for internal waves is solved numerically by the implicit Adams scheme of the third order accuracy. Wave number is found by the shooting method from the necessity of satisfying the boundary conditions (13b). The eigenfunction of $15 \mathrm{~min}$ internal waves of the second mode is shown in Fig. 2, $b$.

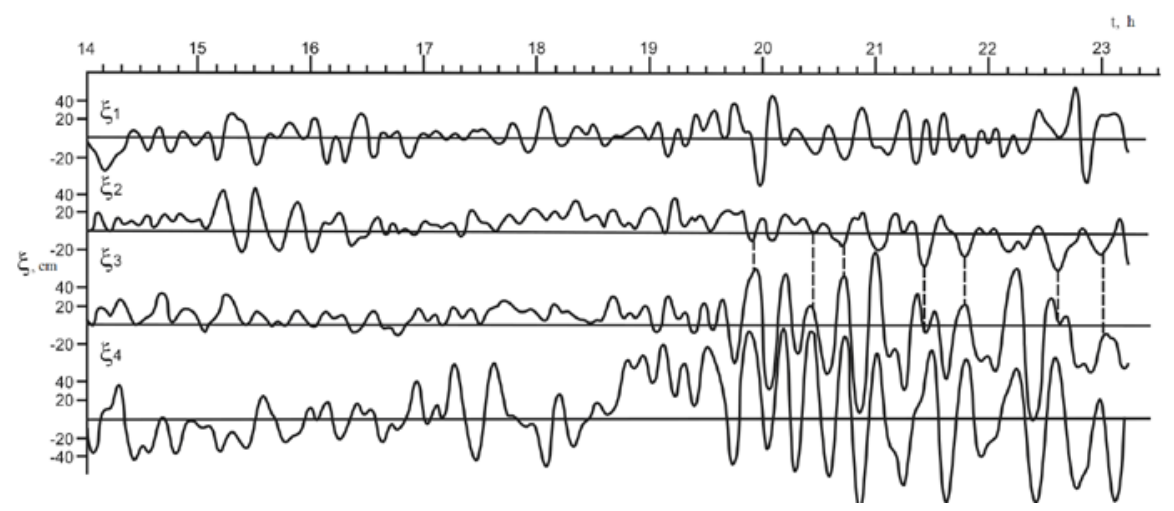

Fig. 1. Time variation of the vertical displacements temperature contours

This implies

$$
A_{1}=\frac{\max \zeta_{3}}{2 \max \left|w_{0} / \Omega_{0}\right|} .
$$


Thus, the amplitude of vertical displacements is proportional to $w_{0}$. According to the experiment data (Fig. $1 ; 2, b$ ), the maximum of $w_{0}$ function correspond to the maximum vertical displacements, i.e. in the experiment the second mode was observed. We calculate a vertical eddy diffusion coefficient $M_{3}$ by the empirical formula, which is valid in the area of continental slope at the Black sea north-west shelf [7]: $M_{3} \cong 8.4 \cdot 10^{-4} N_{c}^{-1} \mathrm{~m}^{2} / \mathrm{s}, N_{c}$ corresponds to Brent-Vaissala frequency in cph. Wavelength of the second mode 15-min internal waves is $195.6 \mathrm{~m}$, typical value of horizontal eddy diffusion coefficient $M_{1}$ is $1 \mathrm{~m}^{2} / \mathrm{s}$. The dispersion curves of the first two modes in the presence and absence of current are shown in Fig. 3.
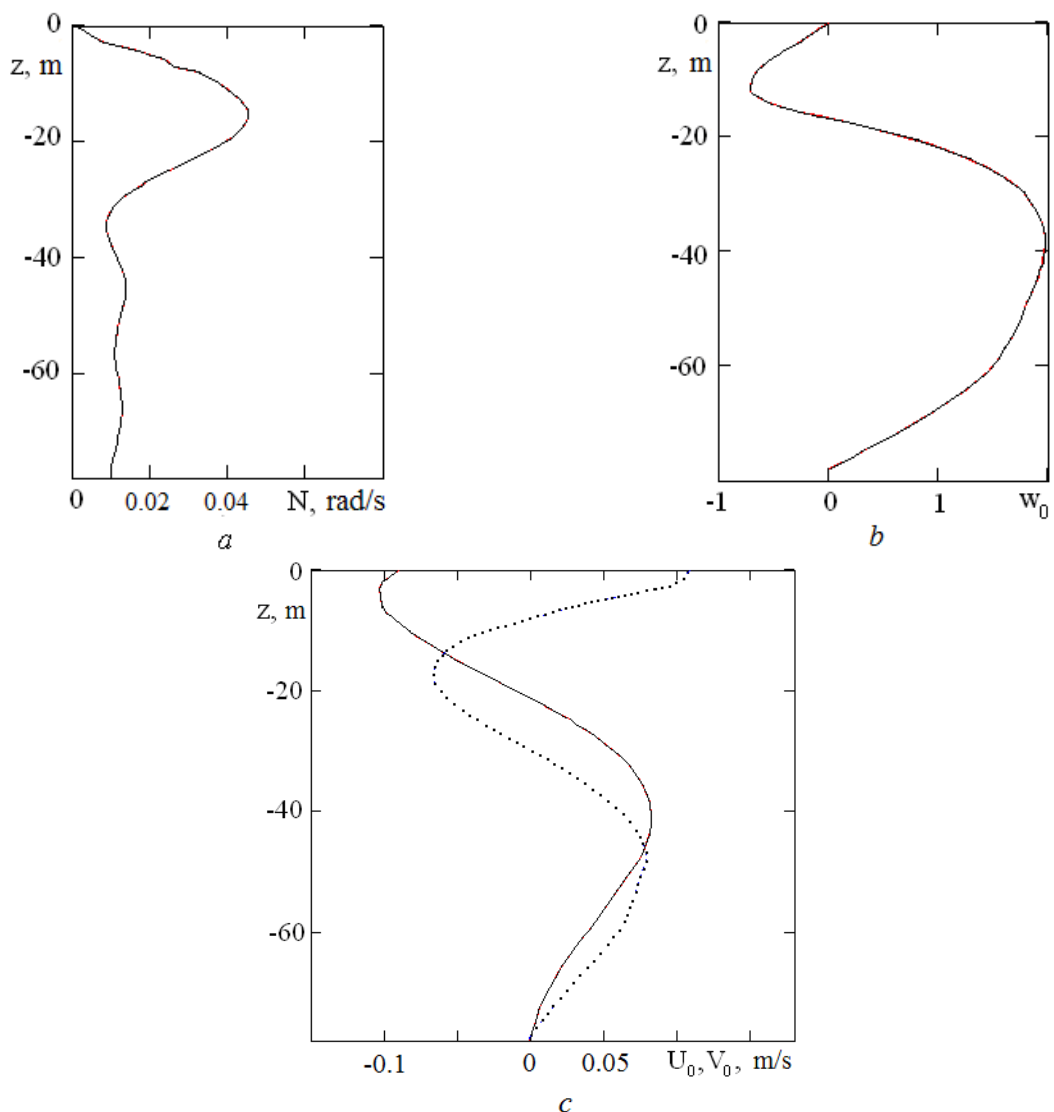

Fig. 2. Vertical profile of Brent-Vaissala frequency - $a$, an eigenfunction of 15 min internal waves $b$, vertical profiles of current velocity components $U_{0}(\ldots), V_{0}(-)-c$ 

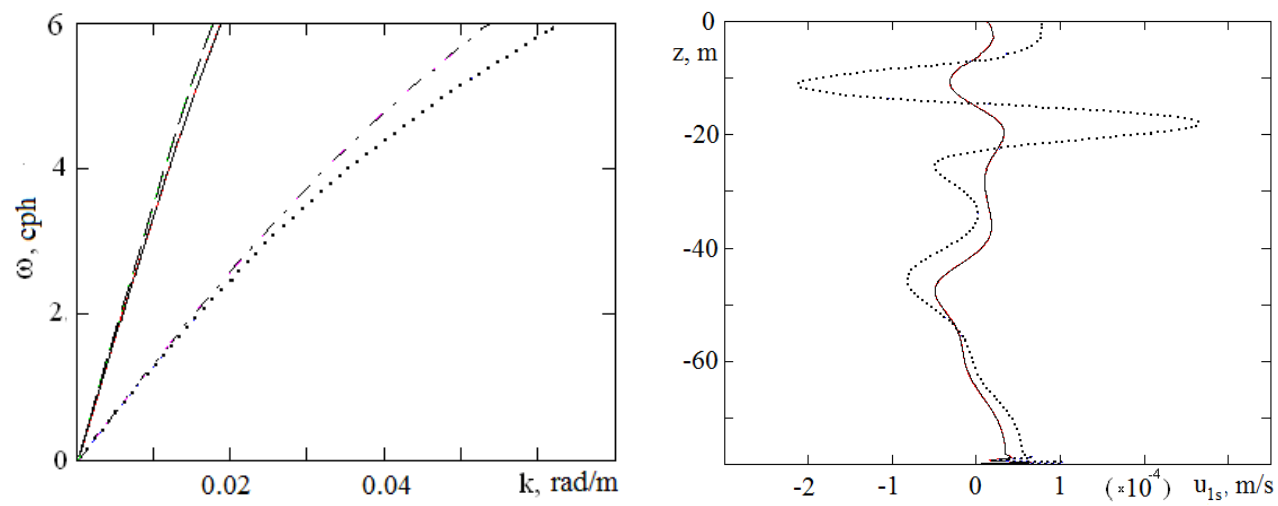

Fig. 3. Dispersion curves: the first mode without current (_- ) and with current (-- ${ }_{-}$); the second mode without current (……) and with current (- - - -)

Рис. 4. Stokes drift velocity in the presence of current

-) and in the absence of current ( ……)

Boundary value problem (17), (18) on the determination of $w_{2}$ function is solved numerically by the implicit Adams scheme of the third accuracy order at $K_{3}=2 M_{3}, K_{1}=2 M_{1}$. We find the only solution, orthogonal $w_{0}$ and wave attenuation decrement $\delta \omega=\omega_{i}$. In case of $15 \mathrm{~min}$ internal waves of the second mode $\delta \omega=-1.46 \cdot 10^{-3} \mathrm{rad} / \mathrm{s}$. Vertical profiles of Stokes drift velocity horizontal component in the presence and absence (dashed curve) of current are shown in Fig. 4. In the presence of current the Stokes drift velocity in modulus is lesser. Stokes drift velocity component, transversal to the direction of wave propagation, differs from zero only with regard to the current (Fig. 5).
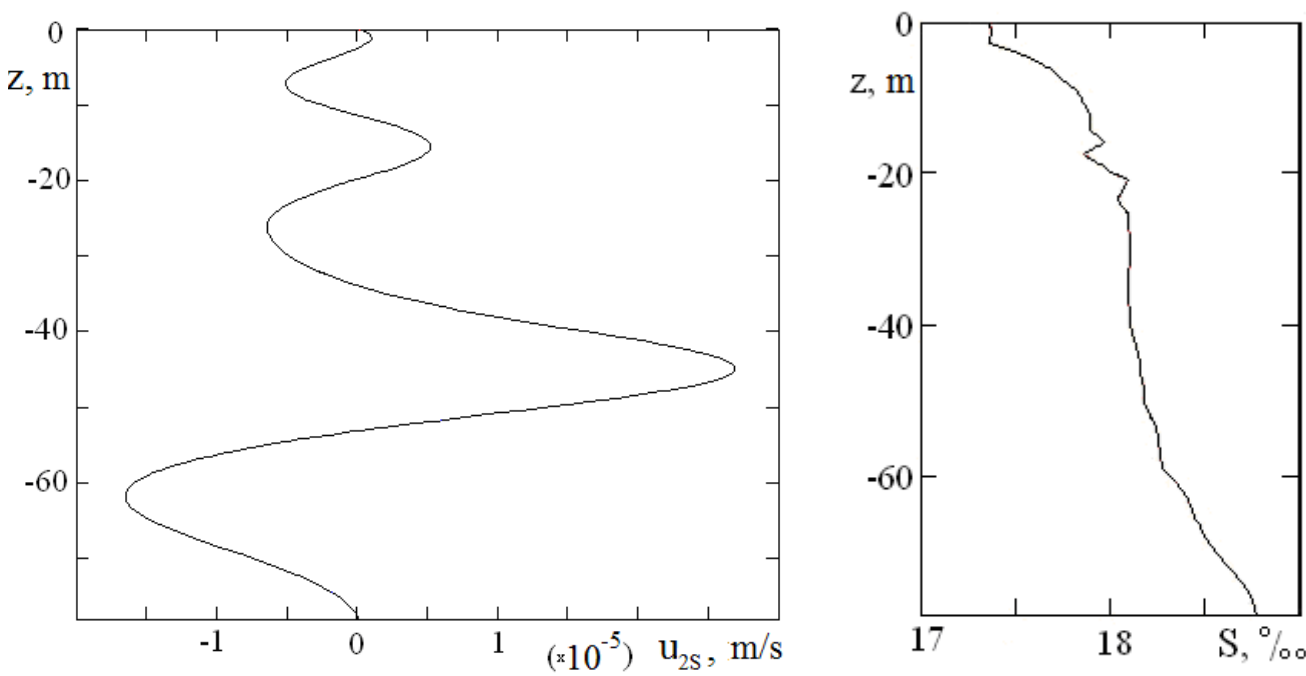

Fig. 5. Stokes drift velocity component, transversal to the direction of wave propagation Fig. 6. Vertical salinity profile 


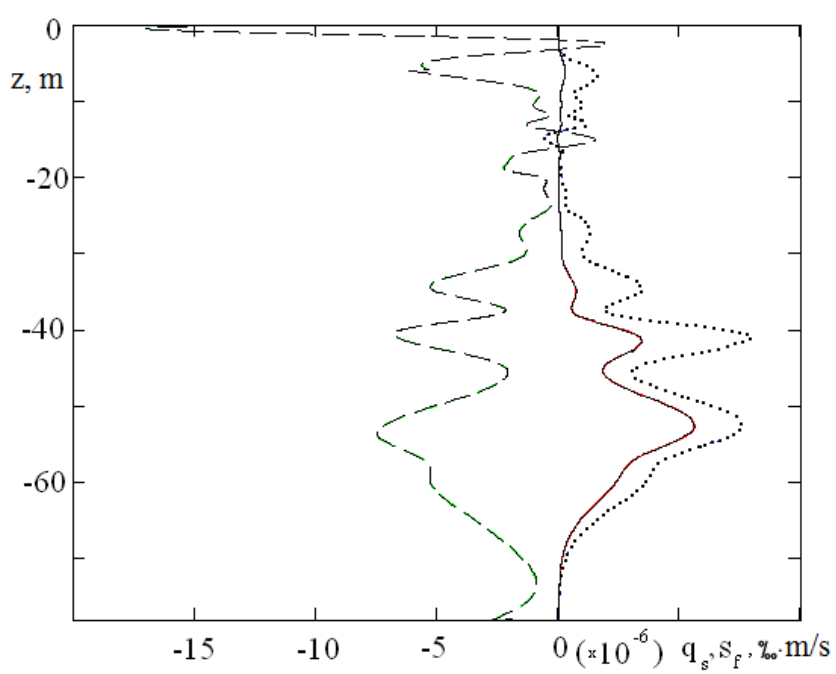

Fig. 7. Profiles of wave and turbulent salt fluxes: wave flux in the presence of current $(-)$ and in the absence of current (……); turbulent salt flux (-- )

Wave salt flux is calculated at the vertical salinity profile, shown in Fig. 6.

Turbulent salt flux is calculated according to the formula $s_{f}=-M_{3} \frac{d S_{0}}{d z}$. Vertical wave salt flux $\overline{u_{3} S}$ for 15 min internal waves of the second mode and a turbulent flux are represented in Fig. 7. In the presence of current the wave salt flux is somewhat lesser than in its absence. In the absence of current a wave flux (dashed line) is comparable in modulus with the turbulent flux at a depth more than $25 \mathrm{~m}$, i.e. outside the surface layer of the maximum salinity gradients.

\section{Conclusions.}

1. With account of eddy viscosity and diffusion the wave salt flux $\overline{u_{3} S}$ differs from zero, and in the presence of current it differs somewhat smaller than in its absence.

2. In the absence of current the wave salt flux is comparable in absolute value with the turbulent flux out of the subsurface layer (where the salinity gradients are maximal).

3. The component of Stokes drift velocity (transversal to the wave propagation direction) differs from zero when the current is taken into account.

\section{REFERENCES}

1. LeBlond, P., Mysak, L., 1981, “Volny v okeane”, Moscow, Mir, part. 2, 363 p. (in Russian).

2. LeBlond, P.H., 1966, "On damping of internal gravity waves in a continuously stratified ocean”, J. Fluid Mech., vol. 25, part. 1, pp. 121-142.

3. Ostrovsky, L.A., Soustava, I.A., 1979, "Verkhniy peremeshannyy sloy kak stok energii vnutrennikh voln [The upper mixed layer of the ocean as an energy sink of internal waves]", Okeanologiya, vol. 19, no. 6, pp. 973-981 (in Russian). 
4. Borisenko, Yu.D., Voronovich, A.G. \& Leonov, A.I. [et al.], 1976, “K teorii nestatsionarnykh slabonelineynykh vnutrennikh voln $v$ stratifitsirovannoy zhidkosti [On the theory of nonstationary weak nonlinear internal waves in stratified fluid]”, Izv. AN SSSR, Fizika atmosfery i okeana, vol. 12, no. 3, pp. 293-301 (in Russian).

5. Grimshaw, R., 1977, "The modulation of an internal gravity wave packet and the resonance with the mean motion”, Stud. In Appl. Math., vol. 56, pp. 241-266.

6. Grimshaw, R., 1982, “The effect of a dissipative processes on mean flows induced by internal gravity-waves packets”, J. Fluid Mech. vol. 115, pp. 347-378.

7. Ivanov, V.A., Samodurov, A.S. \& Chuharev, A.M. [et al.], 2008, “Intensifikatsiya vertikal'nogo turbulentnogo obmena $v$ rayonakh sopryazheniya shel'fa $i$ kontinental'nogo sklona $v$ Chernom more [Intensification of the vertical turbulent transfer near the interface between the shelf and the continental slope in the Black Sea]", Dop. NAN Ukrainy, no. 6, pp. 108-112 (in Russian).

8. Samodurov, A.S., Nosova, A.V. \& Slepyshev, A.A., 2011, "Fizicheskie mekhanizmy intensifikatsii vertikal'nogo obmena $v$ zone sopryazheniya shel'fa i svala glubin [Physical mechanisms of an intensification of a vertical transfer in a zone of interface of a shelf and the continental slope]", Ekologicheskaya bezopasnost' pribrezhnoy i shel'fovoy zon i kompleksnoe issledovanie resursov shel'fa, iss. 25. vol. 2, pp. 190-203 (in Russian).

9. $\quad$ Slepyshev, A.A., 1997, "Protsessy perenosa, obuslovlennye slabonelineynymi vnutrennimi volnami pri nalichii turbulentnosti [Transport Processes Induced by Weakly Nonlinear Internal Waves in the Presence of Turbulence]”, Izv. RAN. Fizika atmosfery i okeana, vol. 33, no. 4, pp. 536-548 (in Russian).

10. Vishik, M.I., Lyusternik, L.A., 1957, "Regulyarnoe vyrozhdenie i pogranichnyy sloy dlya lineynykh differentsial'nykh uravneniy s malym parametrom [Regular Degeneration and Boundary Layer for Linear Differential Equations with a Small Parameter]”, Uspekhi matematicheskikh nauk, vol. 12, no. 5 (77), pp. 3-122 (in Russian).

11. Cherkesov, L.V., 1980, “Gidrodinamika voln”, Kiev, Naukova Dumka, 259 p. (in Russian).

12. Longuet-Higgins, M.S., 1969, "On the transport of mass by time varying ocean current", Deep-Sea Res., vol. 16, no. 5, pp. 431-447.

13. The report on works in 44th cruise (3rd stage) of research vessel "Michael Lomonosov" August, 7th - September, 15th 1985, Sevastopol, MGI NAN Ukrainy, 1985, vol. 1, 135 p. (in Russian). 